\title{
LA UTILIDAD DEL CONTRATO DE OPCION EN EL CODIGO CIVIL DE 1984
}

Miguel Torres Méndez

Una de las nuevas modalidades de contratación que introduce positivamente el vigente Código Civil peruano es el llamado Contrato de Opción. Dicho ordenamiento civil califica este contrato como contrato preparatorio dedicándole varias normas a su regulación.

Este contrato consiste, de acuerdo a la definición contenida en el artículo $1419^{\circ}$ de este Código, en que una de las partes quede vinculada a su declaración de celebrar en el futuro un contrato definitivo y la otra tiene el derecho exclusivo de celebrarlo o no.

El objeto del presente trabajo consiste en investigar la utilidad que conlleva esta modalidad contractual que pudo dar motivo a su legislación en el vigente Código Civil. Como se sabe, toda institución jurídica que es regulada positivamente debe ser útil. Es decir, debe servir para algo. Esta utilidad tiene que darse en esta institución jurídica para que el Código Civil de 1984 la haya incorporado positivamente. Pues de lo contrario, dicha regulación legal no tendrá justificación alguna por no responder a los fines del Derecho.

JAIME GUASP explica este fundamental principio de los fines del Derecho de la siguiente manera: "Los fines del Derecho responden, pues, no a la pregunta del "por qué", sino a la del "para qué" de cualquier institución jurídica" (1). Este mismo autor concluye sobre los fines del Derecho señalando que: "Cabe, en consecuencia, designar correctamente a los fines jurídicos, como los propósitos del Derecho mismo. En principio, una relación o conjunto de relaciones jurídicas se hace siempre para algo: y prescindiendo

(1) Guasp, Jaime. “Derecho”. Madrid 1971, pág. 342. 
del para qué de la materia social que la integra, hay un para qué de la forma que recoge esa materia social y que la convierte o transforma en necesaria, que es el propósito del resultado jurídico total" (2). Para el caso materia de estudio, la legislación del contrato de opción debe servir para algo (ser útil), porque de lo contrario no responderia a los fines del Derecho, en este caso del Derecho Civil peruano regulado en su correspondiente Código.

Como se puede apreciar, lo que en suma vienen a ser los fines del Derecho no es otra cosa que la finalidad de la norma jurídica. Así, LUIS RECASENS SICHES, ilustre teórico del Derecho, señala respecto a dicha finalidad lo siguiente: "Hoy casi todos los teóricos de lo jurídico están de acuerdo en que la finalidad es el motivo que estimula la creación de todo Derecho, y afirman que no hay norma jurídica que no deba su origen a un fin, a un propósito, esto es, al intento de satisfacción de una necesidad práctica" (3). Para luego seguir afirmando: "En fin, la finalidad, el propósito, consiste en producir en la realidad social unos determinados efectos, los efectos que son deseados por considerarlos valiosos: justos, convenientes, adecuados" (4).

Pero para poder saber cuál es la utilidad de esta figura contractual, considero que es conveniente precisar primero la naturaleza juridica de esta institución toda vez que muchos autores confunden esta modalidad contractual con la oferta de carácter obligatorio o irrevocable. Es decir, consideran equivalentes al contrato de opción y la oferta de tal naturaleza. Así, JAIME SANTOS BRIZ señala por ejemplo lo siguiente: "Si estructuramos la oferta contractual como una declaración de voluntad vinculante para el que la fórmula por un cierto plazo, durante el cual puede aceptarla o no la persona quien va designada, prácticamente hemos descrito el denominado contrato de opción" (5). Asimismo, MANUEL DE LA

(2) Ibid, pág. 342 .

(3) Recaséns Siches, Luis. "Introducción al Estudio del Derecho". México 1970. pág. 121.

(4) Ibid, pág. 121.

(5) Santos Briz, Jaime. "La Contratación Privada". Madrid 1966, pág. 119. 
PUENTE Y LAVALLE afirma lo siguiente: "En realidad, el contrato de opción tiene como efecto el que una de las partes formule a la otra una oferta de contrato, de tal manera que, en este sentido no cabe distinguir entre oferta de contrato y contrato de opción, tan es así que se ha sugerido en este trabajo designar el segundo con el nombre de contrato de ofertar' (6).

Como puede apreciarse, tal equivalencia y equiparación se debe a que tanto el contrato de opción como la oferta irrevocable producen los mismos efectos jurídicos. Es decir, producen efectos jurídicos idénticos.

Sobre el particular, considero que, como puede comprobarse, la única diferencia pero de total importancia, es que el contrato de opción, como tal, es un acuerdo de voluntades y la oferta irrevocable, como tal a su vez, es sólo una declaración unilateral de voluntad. Es decir, en pocas palabras, tal única diferencia estriba en que la primera institución jurídica es un contrato y la segunda no. Y esto se debe pues a que, como puede apreciarse, el primero es un acto jurídico plurilateral y el segundo un acto jurídico unilateral.

Le diferencia pues, es una diferencia de estructura. Es decir, son dos supuestos de hecho diferentes (acuerdo de voluniades/declaración unilateral de voluntad) los que configuran a estas dos instituciores jurídicas. Poseen pues dos "fatticpecie" diferentes como dirían los italianos.

Tal diferencia la concibe y la explica bien LUIS DIEZ-PICAZO de la siguiente manera: "Desde el punto de vista de su finalidad, el contrato de opción guarda una cierta semejanza como ya vimos con la oferta irrevocable, pero se diferencia de ella en que en la oferta hay sólo una declaración unilateral de voluntad, la del oferente, y por consiguiente una única vinculación, la suya, mientras que en la opción hay un negocio bilateral, que obliga a ambas par- 
tes y puede, por tanto, determinar para el beneficiario unos específicos deberes, como es, en su caso, el pago del premio" (7).

Es importante en consecuencia aclarar y remarcar bien esta importante diferencia que descubre de esta manera la naturaleza jurídica de esta institución en el sentido de que se trata o es un contrato. No cabe, por lo tanto, igualar o equiparar jurídicamente a este contrato con la oferta obligatoria. El hecho de que ambas instituciones produzcan los mismos efectos jurídicos no significa o quiere decir que éstas sean iguales o las mismas jurídicamente.

Ahora bien, la determinación de la naturaleza de esta institución no se agota en señalar que se trata de un contrato, sino que es necesario además señalar qué caracteres revisten a esta institución jurídica como contrato. Tal necesidad se hace en realidad imperiosa por cuanto existe también una errada confusión en gran parte de la doctrina contractualista sobre uno de los caracteres de este contrato. Esta errada confusión consiste en señalar que el contrato de opción es "unilateral" entendiendo este término en referencia al número de partes que intervienen en la celebración del contrato. RODOLFO SACCO pone en evidencia esta errada confusión, integrándose en ella, de la siguiente manera: "La opción es definida por todos como un contrato unilateral. Deberá, pues, perfeccionar se cuando se perfeccione la declaración is la cual se sujeta, sin necesidad de aceptación por parte del opcionista" (8).

Resulta obvio darse cuenta que esta apreciación es totalmente equivocada, por cuanto de la denominación misma de "contrato unilateral" -entendiéndose este término en referencia al número de partes- ésta resulta totalmente contradictoria ya que, como es de elemental conocimiento, todo contrato sólo puede darse entre más de una parte, es decir, necesariamente tiene que ser entre dos o más partes, es jurídicamente imposible que un contrato pueda celebrarse entre sólo una parte. Por tal razón, es completamente sabido que parte de la esencia del contrato es que éste es un acto juridico "plurilateral" como ya anteriormente se ha mencionado.

(7) Diez-Picazo, Luis. "Fundamentos de Derecho Civil Patrimonial". Tomo I Madrid 1979, pág. 217.

(8) Sacco, Rodolfo "Il Contratto”. Torino 1975, pág. 710. 
Por ser esta situación de la "unilateralidad" del contrato de opción jurídicamente imposible, es menester, en consecuencia, corregir este error con su necesaria y correspondiente aclaración que descubra y demuestre su inexactitud así como la situación que ha de ser la exacta y correcta.

En primer lugar, es necesario indicar que el contrato en el cual para su perfeccionamiento sólo es necesario la voluntad del optante es, evidentemente, el contrato definitivo y no el de opción que es el contrato preparatorio de aquél. Esto si bien viene a ser una verdad de perogrullo, aun así es necesario remarcarla por cuanto hay quienes no perciben bien esta distinta situación incurriendo en otra errónea e indebida confusión. Tal es el caso, precisamente, de RODOLFO SACCO. Dicho autor, como puede apreciarse en el últi mo tex to doctrinario que se ha citado, llega a afirmar, después de definir al contrato de opción como contrato unilateral, que este contrato se perfecciona - vale decir se celebra- cuando se perfecciona la declaración a la cual se sujeta, sin necesidad de aceptación por parte del opcionista. En realidad, nada es más inexacto en cuanto al contrato de opción, aquí RODOLFO SACCO incurre en un grave error. En el contrato de opción, como en todo contrato, es necesario el concurso de las voluntades de todas las partes contratantes y no se perfecciona con la sola voluntad de una de ellas. En un contrato de opción entre sólo dos partes contratantes por ejemplo, tal contrato se perfeccionará con la declaración del opcionista $u$ oferente de querer conceder una oferta irrevocable, por un determinado periodo de tiempo, de celebrar en el futuro un contrato definitivo al optante o beneficiado con la oferta, y con la declaración de éste aceptando que le otorguen dicha concesión. Es pues, necesario el concurso de las dos voluntades, por cuanto si la persona a quien se desea otorgar esa concesión no desea que se la otorguen, simplemente rechazará dicha oferta; con lo cual, no se habrá celebrado el contrato de opción.

Por lo tanto, el contrato de opción no se perfecciona pues con la voluntad de una sola de las partes. Esta situación se presenta más bien, como se ha seññalado anteriormente, en la celebración del contrato definitivo, por cuanto, como se sabe, en virtud del contrato preliminar o preparatorio de opción, el optante ha 
quedado habilitado para por su sola voluntad, celebrar el contrato definitivo.

Ahora, esta situación llevaría a pensar que en el caso del contrato definitivo éste sí sería entonces un contrato "unilateral" o de una sola parte, por cuanto si para su perfeccionamiento sólo basta la declaración de voluntad del optante, esto en consecuencia, supuestamente querría decir que el contrato definitivo se estaría celebrando con la intervención de una sola parte. Pero en realidad dicha situación no quiere decir tal cosa, por cuanto como se sabe muy bien eso no puede darse jurídicamente. Lo que pasa en realidad es que la declaración de voluntad del opcionista u oferente para la celebración del contrato definitivo ya ha sido emitida anticipadamente en el contrato de opción y no se necesita, en consecuencia, que la declare nuevamente en la celebración del contrato definitivo.

Y la demostración de esta situación se puede apreciar claramente porque ella se encuentra en el consentimiento contractual. Como se sabe, el contrato se forma cuando se produce el consentimiento contractual y éste consiste en la coincidencia de la oferta y la aceptación. Esto quiere decir que todo contrato debe formarse con la conjunción o coincidencia de oferta y aceptación. De ahí deriva el hecho de que el contrato sea un acto jurídico plurilateral, porque para que se produzca la coincidencia de oferta y aceptación necesariamente tiene que haber, por lo tanto, por lo menos dos voluntades. En consecuencia, tanto en el contrato de opción como en el contrato definitivo debe producirse esta coincidencia de oferta y aceptación o consentimiento contractual. El contrato de opción, como ya se ha señalado anteriormente, se forma con la oferta del concedente $u$ opcionista consistente a su vez en querer conceder $u$ otorgar una oferta de carácter irrevocable a favor del optante para la celebración de un contrato definitivo, y con la aceptación del optante sobre dicha concesión. Ahora, una vez formado o celebrado este contrato, -el contrato de opción-, resulta obvio darse cuenta que con este contrato ya surge o se produce la oferta irrevocable de celebrar el contrato definitivo por parte del opcionista, y ésta es ya, en consecuencia, la declaración de voluntad de esta parte - el contrato definitivo-. El opcionista ha emitido entonces su voluntad anticipadamente para la celebración del contrato definitivo tal como ya se había indicado antes. 
Pues bien, como ya hay oferta para la celebración del contrato definitivo, sólo falta entonces la aceptación de ella para que llegue a producirse el consentimiento contractual y se perfeccione así el contrato definitivo. Y dicha aceptación, obviamente, depende única y exclusivamente del optante; en tal medida, con su sola y entera voluntad podrá celebrar o no el contrato definitivo. Por eso es que se llega a afirmar que el contrato definitivo se perfecciona con la sola voluntad del optante. Pero, como ha quedado demostrado en base a todo lo expuesto, eso no quiere decir que el contrato definitivo se celebre con la intervención de una sola parte y sea pues, en ese sentido, "unilateral". El contrato definitivo, como todo contrato, se perfecciona con la participación o con las voluntades de todas las partes contratantes. El hecho de que en el perfeccionamiento de dicho contrato oferta y aceptación no coincidan simultáneamente sino que anticipadamente se formule la oferta y estando ésta vigente el optante pueda con su sola voluntad perfeccionar el contrato con la aceptación, no quiere decir pues que este contrato sea perfeccionado "unilateralmente". Intervienen, pues, en la formación de este contrato tanto la voluntad del opcionista como la del optante y no la de uno solo.

Esta es entonces la verdadera situación que acontece en el perfeccionamiento del contrato definitivo. El optante, para la celebración de este contrato, ya no necesita nuevamente del concurso de la voluntad del opcionista porque dicho concurso ya ha sido dado pues en la oferta que se formula en el contrato de opción. Tal situación la describe GIUSEPPE TAMBURRINO de la siguiente manera: "El destinatario de la opción no tiene necesidad de compeler a la otra parte para que preste su consentimiento en el contrato definitivo, ya que con su simple aceptación el contrato está,..." (9). De igual forma, MANUEL DE LA PUENTE Y LAVALLE dice al respecto lo siguiente: "..., de tal manera que el contrato definitivo se celebrará cuando se acepte la oferta que se formula mediante el contrato de opción" (10).

(9) Cita de Fernando Fueyo, "Derecho Civil". Tomo V, Vol. II-2, Santiago de Chile, 1963, pág. 39.

(10) De la Puente y Lavalle, Manuel. "Estudios del Contrato Privado". Tomo I, Lima 1983, pág. 437. 
Habiendo ya resuelto esta errónea confusión, se puede ahora ya señalar los verdaderos caracteres que revisten a esta institución jurídica del contrato de opción. Tres son los principales caracteres de este contrato, caracteres que se infieren de la descripción dada en el artículo $1419^{\circ}$ del Código Civil de 1984 . En primer lugar, es preparatorio; es decir, se celebra para en el futuro celebrar otro contrato. En ese sentido el contrato de opción es preparatorio de otro contrato, el definitivo. Asimismo, este contrato tiene la principal característica de que una de las partes queda vinculada a su declaración de celebrar en el futuro un contrato definitivo y la otra tiene el derecho exclusivo de celebrarlo o no tal como exactamente lo describe el artículo $1419^{\circ}$ del vigente Código Civil. Y, en tal virtud, el contrato de opción puede ser tanto de prestaciones recíprocas como de prestación unilateral. Será de prestaciones recíprocas si existe, por haberse pactado así, a cargo del optante una contraprestación recíproca de la prestación del opcionista que es la oferta irrevocable. Y será de prestación unilateral si simplemente no existe contraprestación alguna a cargo del optante.

Esta es, en consecuencia, la verdadera naturaleza jurídica de esta institución, la de ser un contrato, de carácter preparatorio,

Esta es, en consecuencia, la verdadera naturaleza jurídica de esta institución, la de ser un contrato, de carácter preparatorio, mediante el cual una de las partes queda vinculada a su declaración de celebrar en el futuro un contrato definito (oferta irrevocable) y la otra tiene el derecho exclusivo de celebrarlo o no, pudiendo ser en tal virtud tanto de prestaciones recíprocas como de prestación unilateral.

Ahora que ya se ha precisado y determinado bien la naturaleza jurídica de esta institución, corresponde ahora sí entonces determinar la utilidad de la misma en el Código Civil Peruano.

Como puede apreciarse de su naturaleza jurídica, la característica principal de esta institución, es decir, la situación que más la caracteriza, es la consistente en que una de las partes queda vinculada a su declaración de celebrar en el futuro un contrato definitivo y la otra tiene el derecho exclusivo de celebrarlo o no. JOSE PUIG BRUTAU describe esta principal característica en los siguien- 
tes términos: "La parte que se compromete a permanecer vinculada durante algún tiempo queda enfrentada con otra que está en libertad para dejar perfeccionado el contrato o para desistir de hacerlo durante el tiempo señalado. Esto es lo que propiamente caracteriza a la opción. .." (11). Y esta situación no es otra cosa que la formulación de una oferta de carácter irrevocable por parte del opcionista. En tal medida, se debe concluir pues, como ya resulta obvio darse cuenta, que el contrato de opción tiene por finalidad la formulación, por parte del opcionista, de una oferta irrevocable a favor del optante. $O$ dicho en términos técnicamente jurídicos: el objeto del contrato de opción es la obligación, por parte del opcionista, de formular una oferta irrevocable a favor del optante.

En tal virtud, surge entonces de inmediato la formulación de la siguiente pregunta: ¿tiene algún sentido y utilidad el contrato de opción en las legislaciones civiles en las que se ha adoptado el régimen de obligatoriedad o irrevocabilidad de la oferta? La respuesta, obviamente, aplicándose el razonamiento lógico jurídico, es negativa. No tiene ningun sentido y utilidad del contrato de opción en aquellos ordenamientos civiles que han adoptado dicho régimen, porque, como resulta obvio darse cuenta de acuerdo al objeto o finalidad de este contrato, los mismos efectos jurídicos que se consiguen con un contrato de opción se pueden conseguir con la mera formulación de una oferta.

La demostración de esta situación es por demás totalmente evidente, pues si se tiene que la finalidad del contrato de opción es la formulación de una oferta irrevocable y que de acuerdo al régimen que se ha adoptado la oferta es de por sí irrevocable, resulta evidente darse cuenta entonces que en ambos casos los efectos jurídicos que se producen son los mismos. Estos son, en el contrato de opción como se aprecia, los efectos que produce la oferta irrevocable surgida de este contrato (vinculación del oferente de celebrar el contrato ofertado y el derecho exclusivo del destinatario de la oferta de celebrarlo o no); y, en la oferta irrevocable, los efectos que produce la oferta de tal naturaleza (vinculación del oferente de celebrar el contrato ofertado y el derecho exclusivo del destina-

(11) Puig Brutau, José. "Fundamentos de Derecho Civil". Tomo II, Vol. II. Barcelona 1956, pág. 51. 
tario de la oferta de celebrarlo o no). En consecuencia, se puede apreciar claramente que en ambos casos los efectos jurídicos son los mismos, pues son los efectos que producen la oferta de carácter irrevocable $u$ obligatoria, sin que esto signifique que ambas instituciones sean lo mismo, cosa que ya se ha demostrado al inicio de este trabajo. En tal medida, pues, queda bien demostrado que los mismos efectos jurídicos que se consiguen con un contrato de opción se pueden conseguir con la formulación de una oferta, porque ambas instituciones producen los mismos efectos jurídicos. Dicho lo cual, la mejor manera en que se ha de concluir este razonamiento es repitiendo las mismas palabras con las que RODOLFO SACCO se pronuncia al respecto: "Y ahora no se comprende más la copresencia de estas dos instituciones en un solo ordenamiento" (12).

En efecto, no resulta coherente que en un mismo ordenamiento civil se regulen a la oferta irrevocable y al contrato de opción.

El contrato de opción, en consecuencia, sólo tiene sentido y utilidad en aquellos ordenamientos civiles en los que se ha adoptado el régimen de la no obligatoriedad de la oferta o libre revocación de ella. Pues sólo en estas legislaciones con este contrato se podrán alcanzar efectos jurídicos distintos a los alcanzados o producidos con la oferta, revistiendo estos efectos, por lo tanto, una gran utilidad. Esta situación, al igual que la creada adoptándose el régimen contrario (obligatoriedad de la oferta) resulta ser totalmente lógica y evidente por cuanto resulta ser la situación inversa. Lógicamente, si adoptándose el régimen de la obligatoriedad de la oferta el contrato de opción resulta inútil y sin sentido porque los mismos efectos que se consiguen con este contrato se pueden conseguir con una simple oferta, resulta evidente advertir entonces que todo lo contrario resulta adoptándose el régimen opuesto, el régimen de libre revocación o no obligatoriedad de la oferta. En este régimen, el contrato de opción sí reviste una gran utilidad porque, como se sabe, la finalidad de este contrato es la formulación de una oferta de carácter irrevocable. En tal sentido, mediante este contrato se conseguirá que el oferente formule su oferta de

(12) Sacco, Rodolfo. "Il Contratto". Torino 1975, pág. 710. 
esa manera, irrevocablemente; es decir, se obtiene que el oferente se obligue a mantener su oferta sin poder y tener derecho a revocarla, como normalmente hubiera podido hacer en vista que la oferta es de por sí libremente revocable por haberse adoptado dicho régimen.

En los ordenamientos civiles en los que se ha adoptado el régimen de la libre revocabilidad de la oferta entonces, el contrato de opción sí es muy útil y si resulta coherente su regulación, por cuanto sirve de mucho para el destinatario de la oferta, ya que éste obtiene seguridad respecto a la vigencia de la oferta que le han otorgado en virtud de tal contrato, seguridad que no la tiene con la simple formulación de una oferta a su favor ya que ésta puede ser libremente revocada perdiendo en consecuencia su vigencia.

Habiéndose ya explicado y demostrado esta carencia de sentido y utilidad del contrato de opción en las legislaciones civiles que han adoptado el régimen de la obligatoriedad de la oferta, se debe señalar entonces, inexorablemente, que en tal caso se encuentra el vigente Código Civil Peruano. Pues, como se sabe, dicho Código Civil ha adoptado el régimen de la obligatoriedad de la oferta. Así lo establece en su artículo 1382 que prescribe textualmente lo siguiente: "La oferta obliga al oferente, si lo contrario no resulta de los términos de ella, de la naturaleza de la operación o de las circunstancias del caso". Tal régimen es confirmado, asimismo, por el propio legislador en la exposición de motivos correspondiente en los siguientes términos: "El artículo bajo comentario sanciona la obligatoriedad de la oferta, ..." (13).

La regulación del contrato de opción en el vigente Código Civil peruano, en consecuencia, no resulta coherente, por lo cual, deviene en principio en una institución inútil y carente de sentido.

Ahora, resulta sumamente sorprendente, que el legislador llegue a sostener lo contrario en su exposición de motivos en la que incluso expone un ejemplo. Se procederá en seguida a repro-

(13) Arias Schreiber, Max. "Exposiciôn de Motivos y Comentarios". En: Revoredo de Debakey, Delia. "Código Civil - Exposición de Motivos y Comentarios". Tomo VI, Lima 1985, pág. 42. 
ducir textualmente las argumentaciones del legislador, para luego pasar a demostrar su inexactitud. Sostiene el legislador lo siguiente: "La utilidad del contrato de opción es notoria. Existen, en efecto, circunstancias en que no es posible o conveniente celebrar un contrato definitivo, pero sí resulta provechoso dejar sembrada la posibilidad de que se concrete, en la hipótesis de que así lo decida quien tiene el derecho de ejercitarlo. Así, es contrato de opción aquél por el cual " $A$ " le otorga a "B" el derecho de adquirir un inmueble determinado, al precio que se pacta, dentro de un plazo establecido y que no exceda del límite fijado por el artículo 1423 . Dentro de estas circunstancias puede suceder que:

a. "B" decida ejercitar la opción en el plazo previsto, con lo que queda perfeccionada la compraventa; $y$,

2. "B" deje vencer el plazo de la opción sin ejercitarla o antes de ello renuncie a dicho ejercicio. En uno u otro caso, "A" quedará libre de disponer a su criterio del inmueble que fue materia de la opción y " $B$ " no tendrá obligación de responder frente a " $A$ " por no haber ejercitado la opción o dejado vencer el plazo" (14).

Pero, como se puede apreciar, es evidente y sumamente claro que esa conveniencia que señala el legislador de dejar sembrada la posibilidad de que se contrate en aquellas circunstancias en que no es posible o conveniente celebrar de una vez un contrato se obtiene o alcanza igualmente, en el vigente Código Civil peruano, con la simple formulación de una oferta. Así, en el ejemplo dado por el legislador, "A" podrá igualmente mediante una oferta otorgarle a " $B$ " el derecho de adquirir un inmueble determinado, por un precio determinado y dentro de un plazo que se establece también, resultando en este último punto mucho más ventajoso por cuanto la oferta puede formularse por cualquier plazo no existiendo límite para ello.

Resulta claro entonces que esta conveniencia que señala el legislador (de dejar sembrada la posibilidad de que se contrate en aquellas circunstancias en que no es posible o conveniente celebrar de una vez un contrato) se puede obtener igualmente con la for-

(14) Ibid., págs. 80 y 81. 
mulación de una simple oferta, sin que sea necesario en consecuencia la celebración de un contrato de opción, debiéndose esto a que la oferta, para el vigente Código Civil peruano, es de carácter obligatorio.

Asimismo, las dos posibilidades que señala el legislador que pueden darse celebrándose un contrato de opción, pueden darse igualmente con la formulación de una simple oferta. Analizando una por una tenemos lo siguiente:

1. "B" decide aceptar la oferta en el plazo previsto, con lo que, obviamente, queda perfeccionada la compraventa; $y$,

2. " $B$ " deja vencer el plazo de la oferta sin aceptarla o antes de ello renuncia a dicha oferta, es decir, la rechaza. En uno u otro caso, "A" quedará libre de disponer a su criterio del inmueble que fue materia de la opción y " $\mathrm{B}$ " no tendrá obligación de responder frente a " $A$ " por no haber aceptado la oferta o dejado vencer el plazo.

Queda bien demostrado entonces la inexactitud de lo señalado por el legislador en cuanto a la notoriedad de la utilidad del contrato de opción. Todo lo contrario, lo que resulta notorio es la inutilidad de este contrato de acuerdo a todo lo explicado y demostrado.

Es más, la notoriedad de dicha inutilidad se encuentra en realidad bien acentuada debido a que la mencionada conveniencia que esgrime el legislador (que no es otra cosa que los efectos que produce una oferta obligatoria) resulta más ventajosa si se obtiene mediante una oferta que mediante un contrato de opción, ya que ésta puede formularse por cualquier plazo no existiendo límite para ello como si lo hay en el contrato de opción. Y sobre todo porque también resulta más económico obtener esta conveniencia mediante una simple oferta que mediante un contrato de opción. En efecto, con una oferta, para que ella se dé, simplemente habrá pues que formularla sin que ello implique los gastos y tributos que origina la celebración de un contrato, sobre todo porque generalmente, para efectos de probanza, éstos se celebran por escrito. Esta ventaja económica resulta más trascendente aún en el caso en que el destinatario de la oferta llegue a aceptar y se celebre con ello el 
contrato ofertado. Efectivamente, en el caso de la oferta si el destinatario de ésta llega a aceptarla el resultado de esto es la celebración de un contrato; a diferencia del contrato de opción en el que si el optante llega a aceptar la oferta irrevocable el resultado de esto es la celebración de otro nuevo contrato. En otras palabras, se puede apreciar que en ambos casos se llega al mismo resultado, pero que en el caso de la oferta para alcanzar ese resultado se ha necesitado la celebración de un solo contrato, mientras que en el caso del contrato de opción se ha necesitado la celebración de dos contratos. Lo que implica pues que con una oferta habría un solo gasto y tributación, mientras que con un contrato de opción habrá doble gasto y tributación.

De acuerdo a todo lo obtenido hasta el momento en todo este estudio y análisis, se debe llegar a concluir que el contrato de opción de acuerdo a los motivos que tuvo el legislador para regularlo no ofrece ninguna utilidad dentro del vigente Código Civil peruano. Y habiéndose ya demostrado muy bien que los motivos que esgrime el legislador no son exactos, con lo cual carecen de justificación alguna, es evidente apreciar entonces que su legislación según esos motivos no tiene pues justificación.

Ahora, al no tener justificación por esos motivos la legislación del contrato de opción en el Código Civil de 1984, se está suscitando entonces la situación que se ha precisado en el inicio de este trabajo en el sentido de que esta institución no responde a los fines del Derecho Civil peruano regulado en éste su correspondiente Código.

En efecto, y un último análisis demostrará la validez de esta conclusión, si se tiene que el Código Civil de 1984 ha adoptado el régimen de la obligatoriedad de la oferta, es porque se ha querido alcanzar con ello la finalidad o el fin que ello conlleva, el cual es, que el oferente quede vinculado a su oferta. Con lo cual, para el Derecho Civil peruano, para que se consiga esa finalidad, bastará pues con formular una oferta. Por lo tanto, se puede apreciar claramente que uno de los fines del Derecho Civil peruano es que se obtenga la vinculación del oferente con una simple oferta, sin que se requiera en consecuencia de otra institución jurídica más compleja. Razón por la cual, al regularse el contrato de opción en este mismo Código, ello significa que para alcanzar también la obliga- 
toriedad de la oferta, exista también otra institución jurídica más compleja (pues ella demanda un acuerdo de voluntades), lo cual contradice pues a uno de los fines del Derecho Civil peruano, el cual es en este caso, como se ha demostrado, que se obtenga dicha obligatoriedad con una simple oferta.

Se puede apreciar claramente entonces, que la legislación del contrato de opción en el Código Civil de 1984 no responde a los fines del Derecho Civil peruano, sino por el contrario los contradice.

Sin embargo, resulta que si bien el contrato de opción no responde, como se ha demostrado, a este determinado fin del Derecho Civil peruano; a la postre, sólo por una eventual situación jurídica, este contrato si llega alcanzar a tener una utilidad. Dicha eventual situación jurídica es la posibilidad que consagra el vigente Código Civil peruano de inscribir en el Registro de la Propiedad Inmueble los contratos de opción. Tal posibilidad se encuentra regulada en el inciso 2) del artículo 2019 de dicho Código Civil.

La utilidad que se obtiene entonces con esta situación consiste en que, como se sabe, la inscripción confiere al acto inscrito efectos de erga omnes, es decir, el acto inscrito puede ser oponible a terceros. Así pues, el contrato de opción inscrito, por el cual está latente la celebración de un contrato definitivo que va a versar sobre un bien inmueble; podrá ser oponible frente a terceros que hayan contratado sobre ese mismo inmueble. Esto quiere decir que si el contrato de opción -que ha sido inscrito-de compraventa de una casa por ejemplo, por el cual el propietario opcionista le ofrece irrevocablemente por el plazo de 6 meses la venta de dicha casa al optante, de aceptar la oferta el optante; y, por lo tanto perfeccionarse la compraventa, es éste el único acto válido y eficaz no afectándole ningún acto que se haya constituido con anterioridad. De suceder esto, no tendrán pues validez alguna los actos por los cuales se afecte de alguna manera ese inmueble y que pudieran haber desconocido o perjudicado el contrato definitivo resultante del contrato de opción que fue inscrito.

La utilidad que llega a ofrecer el contrato de opción, en consecuencia, consiste en la posibilidad de inscripción de éste en el Registro de la Propiedad Inmueble, inscripción por la cual el con- 
trato puede ser oponible frente a terceros por conferirle ésta efectos erga omnes. Utilidad que no se obtiene con una oferta.

Ahora bien, como se puede apreciar, esta utilidad que llega a ofrecer el contrato de opción sólo la puede ofrecer cuando este contrato es preparatorio de la celebración de un contrato definitivo que va a versar sobre bienes inmuebles; y no, obviamente, cuando el contrato definitivo va a versar sobre bienes muebles. Dicho en términos técnicamente jurídicos: el contrato de opción sólo ofrece esta utilidad cuando el objeto de la prestación materia de la obligación que va a crear el contrato definitivo sean bienes inmuebles. En tal medida, la utilidad que ofrece este contrato es sólo parcial. Es decir, se da sólo limitadamente, porque sólo sirve para una sola clase de bienes, los inmuebles. La utilidad sería plena y total, obviamente, si se diera para toda clase de bienes y no para sólo una clase de ellos.

Por razón de todo lo expuesto y demostrado, cabe en consecuencia finalizar este trabajo concluyendo que la única utilidad que ofrece el contrato de opción en el Código Civil de 1984 es la posibilidad, cuando el objeto de la prestación materia de la obligación que va a crear el contrato definitivo sean bienes inmuebles, de inscribir dicho contrato en el Registro de la Propiedad Inmueble; razón por la cual, dicha utilidad es sólo parcial. Utilidad que asimismo, como se puede apreciar, no fue precisamente la que tuvo o invocó el legislador para incorporar esta institución en el vigente Código Civil Peruano. De esta manera, fuera de esta única, eventual y parcial utilidad, el contrato de opción dentro del Código Civil de 1984 no ofrece en realidad ninguna utilidad. 